This item was submitted to Loughborough's Research Repository by the author.

Items in Figshare are protected by copyright, with all rights reserved, unless otherwise indicated.

\title{
Packaging of microfluidic devices for fluid interconnection using thermoplastics
}

PLEASE CITE THE PUBLISHED VERSION

PUBLISHER

(c) IEEE

VERSION

VoR (Version of Record)

LICENCE

CC BY-NC-ND 4.0

\section{REPOSITORY RECORD}

Webb, D. Patrick, David A. Hutt, Neil Hopkinson, Paul P. Conway, and Paul J. Palmer. 2019. "Packaging of Microfluidic Devices for Fluid Interconnection Using Thermoplastics". figshare.

https://hdl.handle.net/2134/4620. 
This item was submitted to Loughborough's Institutional Repository (https://dspace.lboro.ac.uk/) by the author and is made available under the following Creative Commons Licence conditions.

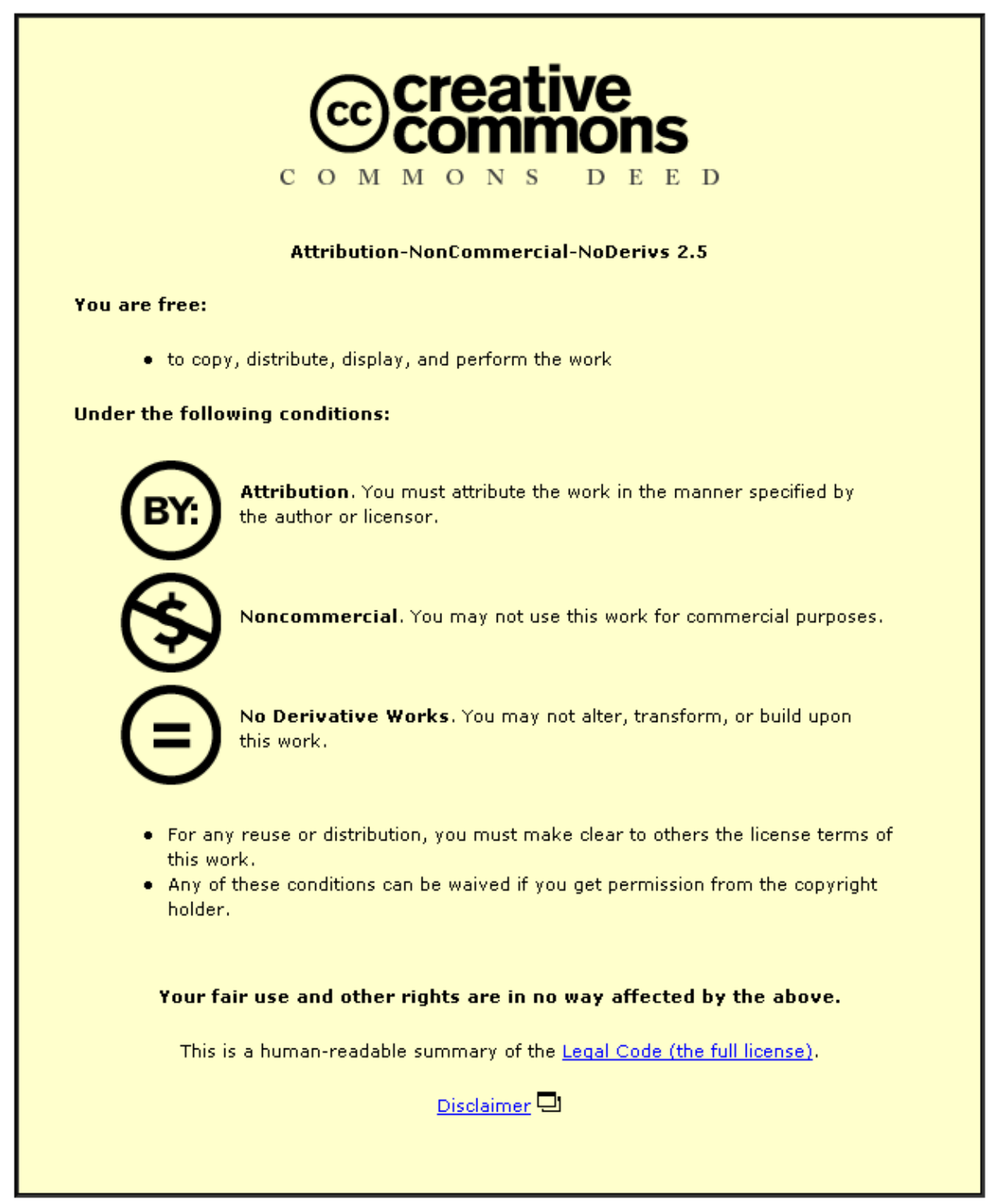

For the full text of this licence, please go to: http://creativecommons.org/licenses/by-nc-nd/2.5/ 


\title{
Packaging of Microfluidic Devices for Fluid Interconnection Using Thermoplastics
}

\author{
D. Patrick Webb, Member, IEEE, David A. Hutt, Senior Member, IEEE, Neil Hopkinson, \\ Paul P. Conway, Senior Member, IEEE, and Paul J. Palmer, Senior Member, IEEE
}

\begin{abstract}
A new packaging method for microfluidic devices is proposed of polymer overmolding to form a fluidic manifold integrated with the device in a single step. The anticipated advantages of the proposed method of packaging are ease of assembly and low part count, making it suitable for low cost and high volume manufacturing. This paper reports the results of a preliminary investigation into this concept. Glass and silicon inserts of $25 \times 20 \mathrm{~mm}$ in size, used to represent microfluidic devices, were overmolded in an injection molding process with a range of polymers. The inserts were found to survive the molding process intact. The adhesion between overmold and insert was investigated by subjecting the interface between the overmold and insert surface to a hydrostatic pressure of up to $100 \mathrm{lbf} / \mathrm{in}^{2}(6.9 \mathrm{bar})$. The durability of the interfacial adhesion to hydrolysis was investigated by immersion in water at $50{ }^{\circ} \mathrm{C}$ for $24 \mathrm{~h}$ before testing. Direct measurements of adhesion strength between polymer and glass were also attempted by tensile tests on lap-jointed samples. The best and most durable adhesion for glass and silicon inserts was found for polyamide (PA) 12, which is a low hygroscopicity PA. The ranking of polymers by their performances in the pressurization tests was consistent with the ranking by the calculated work-of-adhesion values for polymer/glass and polymer/silicon joints.

[2006-0211]
\end{abstract}

Index Terms-Bonding, fluidics, interconnections, packaging.

\section{INTRODUCTION}

$\mathbf{M}$ ICROFLUIDIC devices are made at low cost and with high product consistency through the use of batch processing techniques. While stand-alone microfluidic devices can rely on capillary force to drive flow, to create systems, pressurized flow must be supported, and fluidic connections must be made. Such fluidic interconnects must be mechanically robust and leak tight, the interconnect fluid flow path volumes should be as small as possible, and dead volumes should be eliminated to avoid buildup of contaminants and trapping of bubbles. Materials employed in contact with the fluid must be chemically compatible. Finally, the solution chosen should be suitable for mass manufacture.

Achieving all the aforementioned conditions at low cost at the dimensions required is difficult. Multiple fluid connections

Manuscript received September 27, 2006; revised May 30, 2008. First published February 27, 2009; current version published April 1, 2009. This work was supported in part by the Innovative Manufacturing and Construction Research Centre (IMCRC) at Loughborough University, and in part by the U.K. Engineering and Physical Sciences Research Council (EPSRC) through the 3D Mintegration project. Subject Editor N. F. de Rooij.

The authors are with the Wolfson School of Mechanical and Manufacturing Engineering, Loughborough University, Loughborough, LE11 3TU, U.K. (e-mail: D.P.Webb@lboro.ac.uk; D.A.Hutt@lboro.ac.uk; N.Hopkinson@lboro. ac.uk; P.P.Conway@lboro.ac.uk; P.J.Palmer@lboro.ac.uk).

Color versions of one or more of the figures in this paper are available online at http://ieeexplore.ieee.org.

Digital Object Identifier 10.1109/JMEMS.2009.2013404

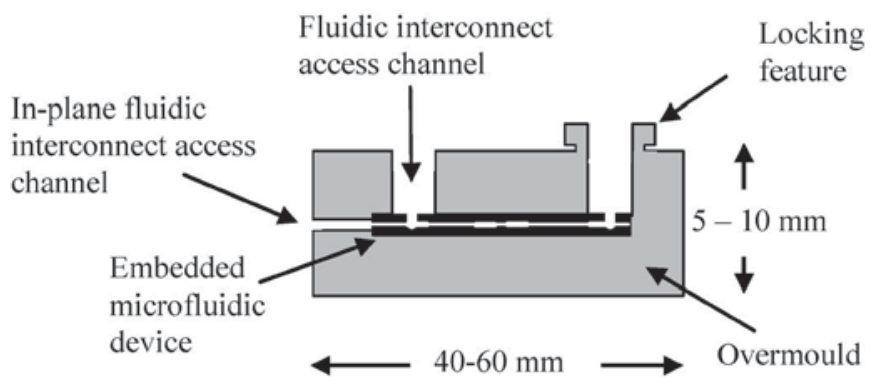

Fig. 1. Concept of molded interconnect to embedded microfluidic device.

may have to be made and sealed, with a positioning tolerance of tens of micrometers. In particular, the use of adhesives for sealing presents the problem of potential blockage of fluid channels through undesired flow of adhesive, along with the requirement to clamp together the device and interconnects during curing.

A method of packaging microfluidic devices to support fluidic interconnects by insert molding is proposed. The concept is illustrated in Fig. 1. The microfluidic device is embedded in a polymer overmold by injection molding or other plastic molding technique. During overmolding, pins within the mold tool are used to create fluidic access channels to the microfluidic device input/output ports. The access channels are several millimeters long and provide the basis for engineering of robust connections to tubes or other means of fluidic interconnect. For example, a locking feature, as shown in the figure, can be incorporated to support a snap-fit-type connector. The connection would thus be both robust and remakeable. In-plane fluid connection could also be supported, removing the necessity to provide interconnection vias through the capping layer of a microfluidic device. A more developed implementation would include fluidic rerouting within the overmold, allowing the interfacing of connector blocks with standardized footprints to nonstandard port layouts. Interconnecting several microfluidic devices could also be achieved, making hybrid microfluidic systems possible (microfluidic "Lego"). A hybrid system could combine, for example, a standardized component manufactured in high volume, such as a silicon micropump, with a custom embossed microfluidic network. The possibility of in-plane fluidic connections increases the flexibility available to the designer of a hybrid system.

The work described in this paper is an investigation into the fundamental materials and process issues, determining the feasibility of the proposed packaging method. These include material choice, integrity of insert after overmolding, and adhesion between insert and overmold. The factors influencing choice of overmold material are discussed. No single molding 
material is likely to service the requirements of all applications; thus, the results of preparing test samples with a number of different thermoplastic polymer resins as the overmold and borosilicate glass and silicon as inserts are reported.

Tests on the quality of the fluid seal between polymer and insert surface before and after accelerated aging environmental conditioning are also reported, together with the effects of the use of an adhesion promoter. Since adhesion between the polymer and insert surface is expected to strongly influence the reliability of the fluid seal, the possibility of making more direct measurements of adhesion strength using lap joints between polymer and glass has been investigated. Preliminary results are reported, and the problems of the method are discussed.

\section{Microfluidics PACKAGING}

The lack of generic packaging is widely recognized as a major barrier to commercialization of microsystems in general, and one that has received relatively little academic attention. For microfluidic applications in particular, several recent reviews have identified fluidic interconnection as a key area for increased research effort [1].

Robust interconnection with good sealing to typical microfluidic port diameters of $100 \mu \mathrm{m}$ or less is difficult to achieve in a way that is friendly to mass manufacture. Two basic methods of sealing external connectors to a microfluidic device exist. One is to use an adhesive, requiring care to be taken to avoid capillary flow of liquid adhesive into the fluid channels. The second is the use of a compliant interposer such as an "o" ring, together with mechanical pressure. This requires extra fine-featured parts to be manufactured and precision assembled. Microfluidic packaging is mostly developed as a custom solution for a particular device. However, some examples of generic solutions to microfluidic packaging have been reported in the literature. One such is a package developed by Sandia National Laboratory in the U.S. [2], where a fluidic manifold block, which may be produced by injection molding, is used as an interface between the microfluidic device and a fluidic circuit board. The sealing between the fluidic manifold, the microfluidic device, and the circuit board requires patterned adhesive preforms.

Interest in hybridization between polymer and glass or silicon microfluidics is indicated by the availability of an integration platform through the European Union-funded microBUILDER program [3]. The platform is for prototyping or small batch applications, rather than being a manufacturing solution.

\section{THEORY OF ADHESION}

The main mechanisms of adhesion described by the various adhesion theories may be grouped under adsorption, mechanical interlocking, diffusion, and electrostatic attraction [4]. In the case of adhesion of a polymer to a smooth glass or silicon surface, it appears that the most important mechanisms to consider are those of adsorption. Adsorption theory relates to the intermolecular forces acting across the interface between two adherends. A closely related topic to adhesion is wetting, which is driven by the same intermolecular forces. Since adhesive bonds are generally formed by the application of a liquid to a solid, good wetting of the solid surface by the liquid is required for intimate molecular contact and, hence, good adhesion after solidification of the liquid.

Intermolecular forces are attributed to a number of mechanisms. Van der Waals forces between electrically neutral atoms or molecules arise due to transient or permanent spatial imbalances in the electronic distributions of charge, i.e., dipole-dipole interactions. Physical adsorption theories of adhesion resolve this force into several components. The dispersion force component is due to the transient formation of dipoles and can occur between atoms or molecules with symmetric (on average) distributions of charge. The dipole-dipole force component either occurs between atoms or molecules with permanent dipoles, or between a permanent dipole and an atom or molecule with a normally symmetric charge distribution upon which a dipole is induced.

Lewis acid-base interactions have also been invoked in physical adsorption. A Lewis base is defined as an electron-pair acceptor, and a Lewis acid is an electron-pair donor. In the context of adhesion, an example of a Lewis acid-base interaction is hydrogen bonding [5], although this could also be considered as a dipole-dipole interaction [4]. There is no consensus in the literature on the relationship between dipole-dipole and Lewis acid-base interactions in adhesion.

Finally, there is chemical adsorption which involves the formation of covalent bonds between adherends. For polymers adhering to inorganics, this is considered to occur mainly when the polymer is a thermoset and polymerizes in situ, for example, with epoxy-based adhesives. Typical covalent bond energies are in the range $63-710 \mathrm{~kJ} \cdot \mathrm{mol}^{-1}$, while Van der Waals forces are weaker with energies up to $42 \mathrm{~kJ} \cdot \mathrm{mol}^{-1}$ [4].

\section{A. Work of Adhesion}

If two dissimilar materials are adhered at an interface, then the thermodynamic reversible work required to separate them is called the work of adhesion. The adsorption theories of adhesion attempt to relate the work of adhesion to the surface energies of the adherends. Conceptually, the surface energy $\gamma$ of a solid material can be regarded as related to the change in the thermodynamic free energy, when the solid is cleaved to create two new surfaces in vacuum [6]. If the material breaks in a completely elastic manner, then the work done on the material to create the new surfaces is

$$
W_{\mathrm{coh}}=2 \gamma
$$

where $W_{\text {coh }}$ is defined as the work of cohesion.

Similarly, an interface between two adhered solid materials $A$ and $B$ has an interfacial energy $\gamma_{A B}$. The work of adhesion $W_{\text {adh }}$ is related to surface and interfacial energies by the Dupré equation

$$
W_{\mathrm{adh}}=\gamma_{A}+\gamma_{B}-\gamma_{A B}
$$

where $\gamma_{A}$ and $\gamma_{B}$ are the surface energies of materials $A$ and $B$, respectively.

Fowkes hypothesized that, to first order, the surface energy of a material can be expressed as the sum of contributions from 
the dispersive and dipole-dipole forces described earlier. This is often written as [7]

$$
\gamma=\gamma^{d}+\gamma^{p}
$$

where $\gamma^{d}$ and $\gamma^{p}$ are the dispersive and polar contributions to the surface free energy, respectively. Other authors suggest that the work of adhesion can be estimated from the knowledge of the components of the surface free energy of two substances using the theory of fractional polarity, one formulation of which by Wendt and Owens is

$$
W_{\mathrm{adh}}=2 \sqrt{\gamma_{A}^{d} \gamma_{B}^{d}}+2 \sqrt{\gamma_{A}^{p} \gamma_{B}^{p}} .
$$

The values for the components of the surface energy of a given material are found by wetting experiments using two or three test liquids of known $\gamma^{d}$ and $\gamma^{p}$.

Fowkes considered dispersive forces to account for most of the work of adhesion, and attributed the remaining work to acid-base rather than polar interactions, i.e.,

$$
W_{\mathrm{adh}}=2 \sqrt{\gamma_{A}^{d} \gamma_{B}^{d}}+W_{a-b}
$$

where $W_{a-b}$ is the contribution to the work of adhesion due to acid-base interactions [6]. Parameters for the acidity and basicity of surfaces are also obtained from wetting experiments or inverse gas chromatography [7] and can be used to calculate values for $W_{a-b}$.

\section{B. Effect of Moisture on Adhesion}

Equation (4) can be extended to cover the case where a liquid $l$ (e.g., water) is present in addition to two materials $A$ and $B$ in contact [4], [6]. The work of adhesion $W_{\text {adh }}^{l}$ is then given by

$$
\begin{aligned}
W_{\mathrm{adh}}^{l}=2\left[\gamma_{l}-\sqrt{\gamma_{l}^{d} \gamma_{A}^{d}}-\sqrt{\gamma_{l}^{p} \gamma_{A}^{p}}-\sqrt{\gamma_{l}^{d} \gamma_{B}^{d}}\right. \\
\left.-\sqrt{\gamma_{l}^{p} \gamma_{B}^{p}}+\sqrt{\gamma_{A}^{d} \gamma_{B}^{d}}+\sqrt{\gamma_{A}^{p} \gamma_{B}^{p}}\right]
\end{aligned}
$$

where $\gamma_{l}, \gamma_{l}^{d}$, and $\gamma_{l}^{p}$ are the total, dispersive, and polar components of the liquid surface energy, respectively. If $W_{\text {adh }}^{l}$ is negative, then the bond between the two materials is thermodynamically unstable in the presence of the liquid and would tend to degrade.

\section{Adhesion Promoters}

One way of attempting to improve moisture resistance of adhesive joints is to use an adhesion promoter. These are usually compatibilizer-type molecules having chemical or other reactivity with both the adherend materials. In this paper, a silane adhesion promoter 3-aminopropyl-trimethoxysilane (APTS) is used to attempt to improve the adhesion of polymers to glass. The chemical structure of APTS consists of a silane head group $\left[\mathrm{Si}\left(\mathrm{OCH}_{3}\right)_{3}\right]$ attached to a short alkane $\left(\mathrm{CH}_{2}\right)$ chain backbone and terminated by an amino $\left(\mathrm{NH}_{2}\right)$ tail group. The coating forms when the silane head group reacts with $\mathrm{OH}$ groups on the glass surface, leaving the amino end group on the chain free to interact with the polymer.

\section{Methodology}

\section{A. Process}

Thermoset molding techniques are extensively used in the field of microelectronics packaging, for example, polymer encapsulation of silicon die by transfer molding. This process is well established and has been extensively characterized for reliability [8]. However, in this paper, the implementation of the proposed method of microfluidic packaging studied is injection molding with thermoplastics. This is because injection molding is capable of large production volumes of precision molded parts and has a short cycle time and many commodity thermoplastics have very low cost. Alternatively, thermoset polymers could be used to implement the concept with, for example, reaction injection molding. The lower temperature and pressure required in reaction injection molding make it attractive from the point of view of insert integrity, but it is a more expensive process.

In a recent work, thermoplastic injection molding has been used to encapsulate electronic modules for automotive application. The process ruggedizes the electronics against harsh environments while saving space in the vehicle, since the electronics can be embedded into a preexisting plastic part [9]. An important factor in this work was the control of built-in stress in the parts through mold design and process parameter optimization. Unbalanced stresses lead to part bending.

\section{B. Materials}

Thermoplastics fall into two broad classes of semicrystalline and amorphous microstructures. Semicrystalline materials tend to show larger volume changes on solidification, while amorphous materials are more susceptible to chemical attack. A third microstructure class is liquid crystal polymers (LCPs), which are well ordered in the molten state and thus have low shrinkage on solidification but tend to be more difficult to process and more expensive.

A wide range of polymers are available for injection molding with different processing and material properties. The variant grades of each base material are formulated to suit particular applications. For microfluidic packaging, the choice of material will be partly determined by the application and chemical compatibility with the working fluid. Consequently, a representative set of materials was chosen for this paper, covering the three microstructures of semicrystalline, amorphous, and LCP. Polarity, processability, and desirable properties such as chemical resistance were also considered in the selection.

The materials and their properties are listed in Table I. The glass-filled Vectra has extremely low shrinkage, combined with broad chemical resistance. The polyamide (PA) material was chosen for good processability, with PA12 being a variety with relatively low hygroscopicity. Polyphenylene sulfide (PPS) is expected to be polar and has good chemical resistance. Cyclic olefin copolymer (COC) was chosen from the point of view of potential applications, as it is transparent and has medical approvals, while acrylonitrile butadiene styrene (ABS) is a common engineering plastic used in the previous work already referred to on overmolding of vehicle electronics. All the materials listed have good resistance to strong acids apart from PA12. 
TABLE I

Molding Materials in This PAPER. Semi-c. = semicrystalline

\begin{tabular}{|c|c|c|c|c|c|}
\hline Material & Full name & Structure & Shrinkage & $\begin{array}{l}\text { Process T } \\
{ }^{\circ} \text { C } \\
\end{array}$ & Other \\
\hline PP & Polypropylene & Semi-c. & \begin{tabular}{r|}
$1-2 \%$ \\
\end{tabular} & 190 & \\
\hline Vectra & (Trade name) & LCP & $0.10 \%$ & 290 & Filled $30 \%$ glass \\
\hline PA12 & Polyamide 12 & Semi-c. & $1-2.2 \%$ & 220 & \\
\hline PPS & Polyphenylene sulphide & Semi-c. & $1.2-1.8 \%$ & 288 & \\
\hline $\mathrm{COC}$ & Cyclic olefin copolymer & Amorphous & $0.6-0.7 \%$ & 190 & Transparent, medical approvals \\
\hline ABS & Acrylonitrile butadiene styrene & Amorphous & $0.4-0.8 \%$ & 220 & Common engineering plastic \\
\hline
\end{tabular}

\section{Test Methods}

In the proposed method of packaging, the quality of the adhesive joint between the overmold material and the surface of the microfluidic device, and its resistance to prolonged exposure to fluid under pressure, is of paramount importance to the reliability of the package. If the seal fails, either undesirable fluid flows will occur or reservoirs of fluid will be created, causing contamination problems. In this paper, two approaches are taken to the evaluation of the quality and reliability of the adhesive seal: A pressurization test reproducing in-service conditions and shear testing to evaluate more directly the strength of the adhesive bonding between polymer and glass insert.

For the in-service condition testing, a pressurized connection was made to a channel on a test specimen. The pressurizing fluid was water, chosen because most microfluidic device working fluids are aqueous and exposure to water is a severe test for adhesive joints, as described earlier. In addition, some specimens were exposed to humidity conditioning before the test to accelerate any moisture-induced degradation. Full details are given in the experimental details section.

In the pressurization test, factors other than the strength of the adhesive seal may play a part in the test performance, e.g., residual shrinkage stress in the polymer overmold. Tensile test measurements on lap-jointed samples were therefore carried out in order to try to obtain a more direct comparison of the adhesion strengths of different polymers. The lap joints were made by treating the polymer under investigation as a hot melt adhesive. The experiment was designed to keep the area of the polymer to glass joints constant from sample to sample and to overcome problems of conducting shear tests with a brittle material such as glass. Full details are given in the experimental details section.

\section{EXPERIMENTAL DETAILS}

\section{A. Inserts}

Glass and silicon inserts of size $25 \mathrm{~mm}$ by $20 \mathrm{~mm}$ were overmolded with the materials in Table I. The glass material was Schott Nexterion B, which is chemically identical to Schott Borofloat, frequently used in microfluidic applications. The glass was supplied with the float and fire-polished sides identified by the manufacturer. The glass inserts were $1 \mathrm{~mm}$ thick and were cut to size by scribing and breaking, followed by washing in water to remove glass fragments and then in methanol before drying in warm air. The cleaning regime was considered to be adequate because of the manufacturer's own

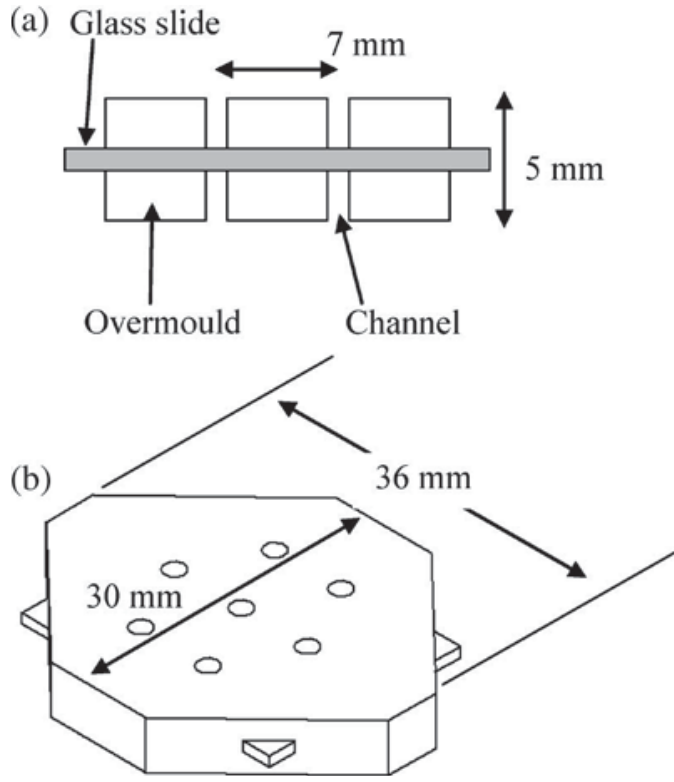

Fig. 2. Molding design used in this paper. (a) Cross section. (b) General view.

cleaning treatment. The silicon material was $\langle 100\rangle$ oriented and was $0.4 \mathrm{~mm}$ thick. The silicon wafers were cut to size using a wafer saw, followed by washing in deionized water, ultrasound treatment in isopropyl alcohol (IPA), a further rinse in deionized water, a final rinse in IPA, and then drying in warm air.

\section{B. Injection Molding}

Injection molding was carried out in a simple vertical miniinjection molding machine with small shot size. Only the nozzle temperature and injection pressure could be controlled on the machine. The same gauge injection pressure of 5.5 bar was used with all materials. The injection temperatures are given in Table I. The mold was not preheated.

The main mold used in this paper was machined in two halves from aluminium and clamped shut with manual pressure for injection. The resultant molding is shown in Fig. 2. A pattern of 14 2-mm-diameter channels, seven on each side of the molding, was produced by the pins in the mold, such that the bottom of the channels was formed by the surface of the glass insert. The mold pins were $2.05 \mathrm{~mm}$ long to allow for variation in the nominal glass thickness of $1 \mathrm{~mm}$ and ensure a tight fit to the glass surface, so that molding material would not flow under the pins during injection. A spacer was used with the silicon inserts to bring them up to 1-mm thickness. The channel to channel spacing was $7 \mathrm{~mm}$. 


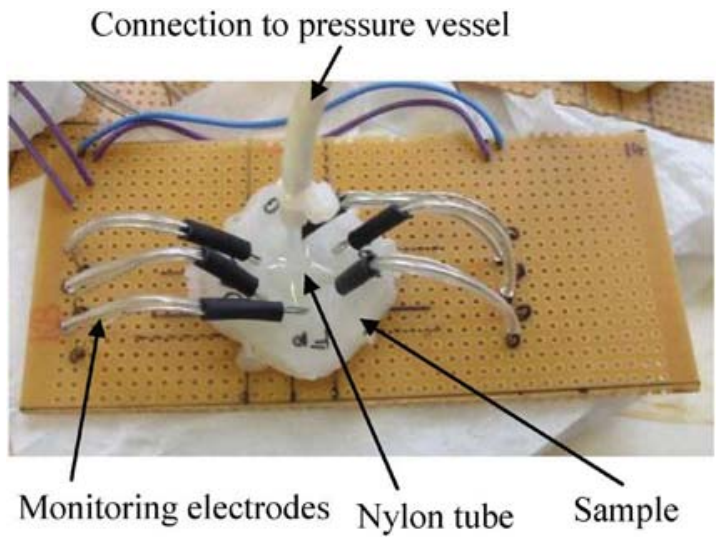

Fig. 3. Pressurization test setup.

\section{Pressurization Tests}

The integrity of the seal formed between the polymer overmold and the glass and silicon inserts was assessed by pressurizing with water at $1.4 \mathrm{bar}\left(20 \mathrm{lbf} / \mathrm{in}^{2}\right)$ at ambient temperature for up to $24 \mathrm{~h}$. Resistance to overpressure was assessed by pressurizing with water at $6.9 \mathrm{bar}\left(100 \mathrm{lbf} / \mathrm{in}^{2}\right)$ for $60 \mathrm{~s}$. The experimental setup is shown in Fig. 3. Connection to the central channel of a molding was made using a 2.4-mm-outer-diameter nylon tube sealed in place with a two-part epoxy adhesive. Some tubes were removed after testing and the moldings examined to ensure that there was no tendency for epoxy to block the tube or channel. The tube was filled with water using a syringe to ensure that there were no bubbles. The assembly was then pressurized and the adjacent channels monitored using a multichannel data logger, for water leakage during the test. Water was detected by a reduction in the resistance between two electrodes inserted into each channel. The test failure criterion was the detection of water. The batch size for the tests was five moldings. All the moldings in a batch were monitored simultaneously. Fresh moldings were prepared for each test.

The pressurization test was carried out on the following:

1) moldings with uncoated slides as inserts, as produced;

2) moldings with uncoated slides as inserts, after humidity conditioning;

3) moldings with silane-coated slides as inserts, as produced;

4) moldings with silane-coated slides as inserts, after humidity conditioning.

Humidity conditioning took the form of soaking moldings in a water bath at $50{ }^{\circ} \mathrm{C}$ for $24 \mathrm{~h}$. This was intended to reproduce the humidity test conditions in the Mil-F-48616 standard for testing of adhesion of lens coatings. Care was taken to remove bubbles from the channels after immersion.

\section{Silane Coating}

Glass inserts were coated with silane by immersion in a dilute solution (less than $10-\mathrm{mM}$ concentration) of the APTS in a mixture of $95 \%$ methanol $/ 5 \%$ deionized water. The inserts were left in the solution for $2 \mathrm{~h}$, then removed and rinsed in methanol, and dried in warm air.
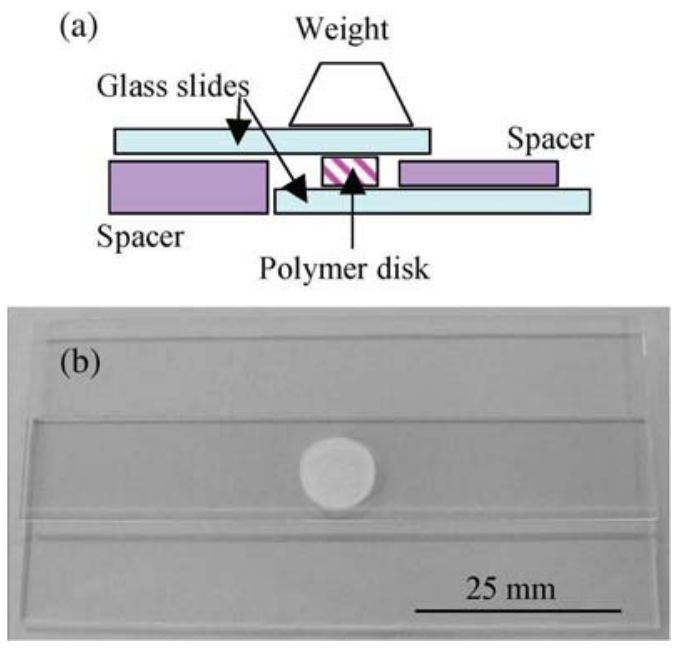

Fig. 4. (a) Method of production of lap-jointed samples. (b) Finished sample.

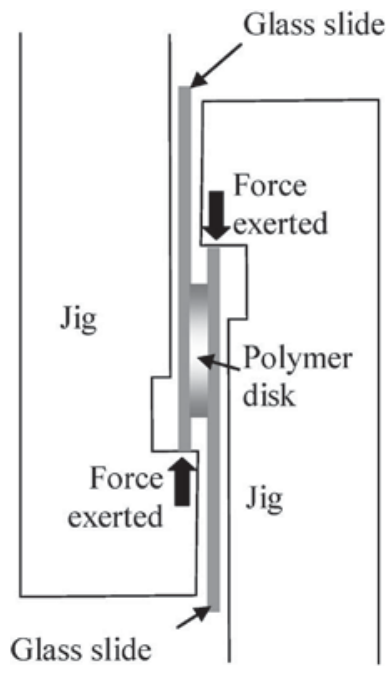

Fig. 5. Lap joint tensile test jig.

\section{E. Lap Joint Testing}

The method of making the lap-jointed samples is shown in Fig. 4. A quantity of disks of polymer $6 \mathrm{~mm}$ in diameter and $1.2 \mathrm{~mm}$ in thickness was first produced by injection molding. A proportion of the disks was then cut into quarters by hand. To make a lap-jointed sample, a full or quarter disk of polymer was sandwiched between two microscope borosilicate glass slides, together with a spacer, and a weight of mass of $30 \mathrm{~g}$ was placed on the top slide directly over the polymer disk. The assembly was placed in an oven preheated to $30^{\circ} \mathrm{C}$ above the processing temperature of the polymer, as listed in Table I, for $15 \mathrm{~min}$. In the oven, the polymer disk melts, and the top slide collapses onto the spacers, compressing the polymer between the two slides. The samples were made with the finishes of both the glass surfaces involved in the joint being the same, i.e., either both fire polished or both float.

The tensile tests were carried out using a jig designed to exert compressive pressure on the edges of the glass slides, as shown in Fig. 5, to take advantage of the increased strength of glass in compression compared to tension. Designing the experiment so that the shearing force is applied to the long edge of the glass 
TABLE II

Pressurization Test Results For Overmolded Glass Inserts ( $24 \mathrm{~h} ; 1.4 \mathrm{bar}$ ). Batch Size of Five SAmples

\begin{tabular}{|c|c|c|c|c|c|c|}
\hline Coating & Conditioning & Vectra & PA12 & PPS & $\mathrm{COC}$ & ABS \\
\hline Uncoated & As made & No failures & $\begin{array}{l}1 \text { failure } 17 \mathrm{hrs} \\
4 \text { No fail }\end{array}$ & All immediate fail & $\begin{array}{l}3 \text { immediate failure } \\
1 \text { fail } 4 \mathrm{~h} 20 \\
1 \text { no failure }\end{array}$ & $\begin{array}{l}4 \text { immediate fail } \\
1 \text { fail after } 2 \& 1 / 2 \mathrm{hrs}\end{array}$ \\
\hline Uncoated & Humidity conditioned & $\begin{array}{l}4 \text { immediate fail } \\
1 \text { no fail }\end{array}$ & $\begin{array}{l}1 \text { immediate failure } \\
1 \text { fail } 7 \text { hrs } \\
3 \text { no fail } \\
\end{array}$ & Not performed & Not performed & Not performed \\
\hline Coated & As made & Not performed & Not performed & Not performed & No failures & All immediate fail \\
\hline Coated & Humidity conditioned & $\begin{array}{l}1 \text { immediate failure } \\
4 \text { no fail }\end{array}$ & \begin{tabular}{|l|}
3 immediate fail \\
1 failure $1 \mathrm{hr}$ \\
1 failure $2 \& 1 / 2 \mathrm{hrs}$
\end{tabular} & Not performed & All immediate fail & Not performed \\
\hline
\end{tabular}

slides helps reduce the unwanted bending moment stress on the sample. An Instron 3366 tensile test machine was used for the shear tests, at a screw speed of $1 \mathrm{~mm} / \mathrm{min}$.

\section{Results}

\section{A. Overmolding of Inserts}

Overmolding of the inserts was successfully carried out without breaking the glass or silicon. Some care had to be taken over the degree of clamping force holding the mold shut, to avoid cracking the insert while still preventing excessive flash. In practice, sprung pins may be required to reduce the transmission of the clamping force to the insert. An important factor in the survival of the inserts is the distribution of residual stress in the moldings. In preliminary work with a different design of mold, where glass slides were overmolded on one side only with polypropylene, the uneven distribution of residual stress caused the molding to bend and the glass to shatter.

There was little tendency for molding material to flow under the pins. In general, feature replication was good, and few moldings exhibited sink marks, despite the lack of temperature control on the mold. In initial trials, some moldings were made with channels $0.8 \mathrm{~mm}$ in diameter and $4.1 \mathrm{~mm}$ long. There seems no reason why even narrower channels could not be made. The simple nature of the injection molding machine made it difficult to remove air from the melt, and bubbles could be seen in some of the translucent moldings. Bubbles would tend to reduce performance in the pressurization tests, for example, by reduction of bonded area, so that the results reported in this paper might be regarded as a conservative indication of performance.

\section{B. Pressurization and Overpressurization Tests}

The results of the pressurization tests with glass are summarized in Table II. Most samples either survived the full 24-h duration of the test or failed immediately on application of pressure. No correlation between the type of glass surface (fire polished or float) and performance was seen. The best performance was seen with Vectra, which exhibited no failures prior to humidity conditioning. Performance was degraded to four failures out of five samples by the humidity conditioning, but silane coating of the glass reduced the failure rate to one
TABLE III

OVERPRESSURIZATION TEST RESULTS FOR OVERMOLDED GLASS INSERTS (60 s; 6.9 bar). BATCH SIZE OF FIVE SAMPLES

\begin{tabular}{|l|l|l|l|}
\hline $\begin{array}{l}\text { Silane } \\
\text { Coated }\end{array}$ & $\begin{array}{l}\text { Humidity } \\
\text { Conditioned }\end{array}$ & Vectra & PA12 \\
\hline No & No & 5 fail & 4 no fail \\
\hline No & Yes & 5 fail & $\begin{array}{l}1 \text { no fail } \\
4 \text { fail }\end{array}$ \\
\hline
\end{tabular}

TABLE IV

PRESSURIZATION TEST RESUlTS FOR OVERMOLDED Silicon InSERTS ( $24 \mathrm{~h}$; $1.4 \mathrm{bar}$ ). BATCH Size OF Five SAMPLES

\begin{tabular}{|l|l|l|l|}
\hline $\begin{array}{l}\text { Silane } \\
\text { coated }\end{array}$ & $\begin{array}{l}\text { Humidity } \\
\text { treated }\end{array}$ & Vectra & PA12 \\
\hline No & No & 5 immediate fail & 5 no fail \\
\hline No & Yes & & $\begin{array}{l}2 \text { immediate fail } \\
3 \text { no fail }\end{array}$ \\
\hline
\end{tabular}

sample after humidity conditioning. The PA12 performed well without a silane coating, with one failure before humidity conditioning and only two failures afterward. The silane coating actually made the performance worse, with all samples failing almost immediately or shortly after the start of the pressurization test following humidity conditioning. PPS moldings of glass without silane all failed; moreover, the moldings all exhibited severe cracking on cooling, probably due to residual stress. Silane-coated glass was not tested, since failure was probably due to the cracking rather than nonadhesion between overmold and glass. The ABS samples failed all tests with the silane coating, having no effect on performance. A surprising result is the performance of the COC samples with silane coating, where no failures occurred before humidity conditioning. Since COC is an olefin, it seems unlikely that there can be an interaction between the overmold material and the amine tail group of the silane molecules bonded to the glass. However, all the COC samples with silane coating failed after exposure to humidity conditioning.

Glass inserts overmolded in Vectra and PA12 were subjected to overpressurization, and the results are presented in Table III. None of the Vectra samples survived the tests, but the as-made PA12 samples performed well. Only one PA12 sample that had been humidity treated survived the test.

The results of pressurization tests on silicon inserts are presented in Table IV. Only PA12 and Vectra samples were made. No correlation between the type of silicon surface 


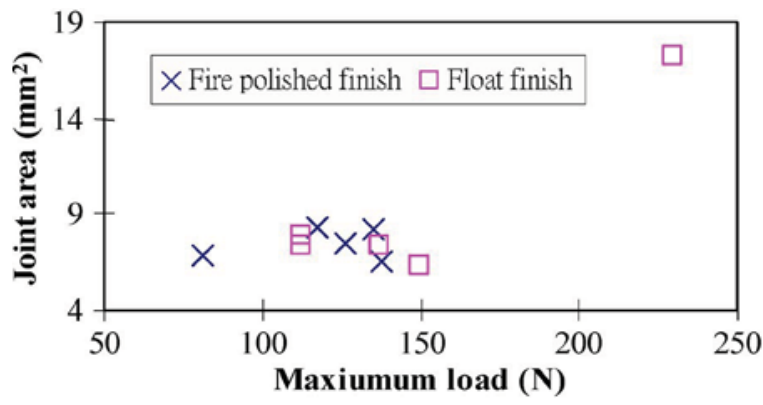

Fig. 6. Maximum load in tensile test of borosilicate glass and PA12 lapjointed samples.

(rough or polished) and performance was seen. While the Vectra appeared to form no seal to the silicon surface, the PA12 performed even better than with glass inserts, with three out of five samples exhibiting a good seal even after humidity conditioning.

In early trials with polypropylene and glass inserts, a complete lack of adhesion between overmold and insert was observed. This was demonstrated with several moldings by placing a droplet of an aqueous dye in the central channel of each molding. The dye, which is visible through the translucent polypropylene, was observed to wick over the whole surface of the glass insert.

\section{Tensile Tests}

Lap-jointed samples were made in batches of ten using the polymers listed in Table I. The only durable joints were formed using PA12, with samples made using the other polymers falling apart spontaneously. This result correlates with the performance in the pressurization tests for uncoated inserts in the cases of PA12, PPS, COC, and ABS. However, it is surprising that Vectra did not adhere. This may be because Vectra is a shear thinning material; thus, the degree of material flow in the joint formation process is insufficient to produce intimate contact between the polymer and glass surfaces.

In tensile testing the PA12 samples, the glass was found to break before the joint could shear when using full size PA12 disks. Further samples were made using the disks cut into quarters by hand. This had the drawback of increasing the variability in the joint areas. The estimation of joint areas was made from micrographs of the samples taken before shear testing. The results of tensile testing on a batch of ten samples made with quarter size disks are shown in Fig. 6. The average breaking shear strength was $16.7 \pm 3.6 \mathrm{MPa}$. The shear occurred at the glass/PA12 interface in all samples.

The scatter in maximum load in Fig. 6 is larger than the scatter in the estimated areas. This may be because the actual adhered area is smaller than the area of the collapsed plastic quarter disk. The manual tilting of some of the samples, in the as-prepared state, under the microscope illumination revealed a slightly darker region covering $1 / 2$ to $2 / 3$ of the total area of the polymer face. This region may be the actual adhered area, but was difficult to photograph. The region could not be identified from the surface of the polymer after shear.

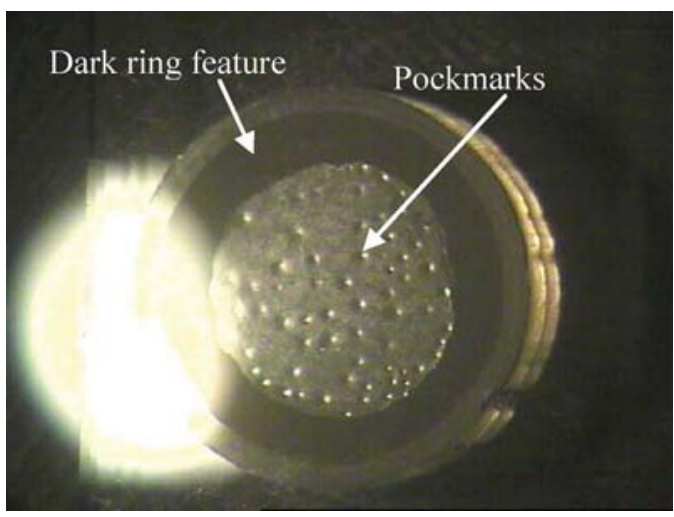

Fig. 7. Dark ring feature and pockmarks in as-prepared PA12 lap joint, tilted under the microscope.

PA12 lap-jointed samples were also subjected to humidity conditioning through immersion in a water bath at $50{ }^{\circ} \mathrm{C}$. A batch of ten quarter disk samples fell apart after 30 min of immersion. Out of a batch of 12 full-sized disk lap joints, six fell apart on removal after $1 \mathrm{~h}$ of immersion. Of the remaining six samples, one was removed after each of 1, 2, 3, and $4 \mathrm{~h}$ of immersion. The final two samples were removed after $24 \mathrm{~h}$. All the surviving samples were tensile tested, and in each case, the glass broke before the joint could shear.

Manual tilting under the microscope of the full disk samples, in the as-prepared state, revealed a dark ring around the periphery of the joints in the samples which fell apart; see Fig. 7. The dark ring was not seen with the samples which did not fall apart. The ring was interpreted as being the region of adhesion. A ring pattern of adhesion may form because air or moisture bubbles trapped in the PA12 disk are released on melting and rise to the interface between the top glass slide and the polymer, occupying the center of the joint. This theory is borne out by the presence of features resembling pockmarks in the central region of the joint, visible in the figure, which are probably due to bursting bubbles.

\section{DISCUSSION}

Table $\mathrm{V}$ shows the values of the work of adhesion to glass and silicon of some of the polymers used in this paper, calculated using (4). The values of the components of surface energy of the polymers, glass, and silicon in the table are from the literature (PP [10], PA12 [11], Vectra [5], PPS [12], and glass and silicon [13], and they were measured by the liquid wetting methods referred to in Section III-A. The values for the work of adhesion broadly reflect the results of the pressurization tests, with PA12, which is the best performer, having the highest works of adhesion, while polypropylene, which did not adhere at all, has the lowest. The work of adhesion for PPS to glass is higher than for Vectra; thus, the poor performance of PPS in the tests may be due to cracking induced by residual stress rather than low adhesion strength, as has already been stated.

The values for the work of adhesion do not shed light on why lap-jointed samples were only successfully formed from PA12, since the work of adhesion to glass for PPS is close to that of PA12. Residual-stress-induced cracking was not observed to 
TABLE V

SURFACE ENERGIES AND DERIVED WORKS OF ADHESION

\begin{tabular}{|l|r|r|r|l|r|r|r|}
\hline \multicolumn{7}{|c|}{$\begin{array}{l}\text { Work of adhesion to: } \\
\text { Surface Energy }\left(\mathrm{mJm}^{-2}\right):\end{array}$} & \multicolumn{2}{l|}{ Glass } & \multicolumn{2}{l|}{ Glass } \\
\hline Material: & $\gamma$ & $\gamma^{\mathrm{d}}$ & $\gamma^{\mathrm{p}}$ & $W_{A}\left(\mathrm{mJm}^{-2}\right)$ & $W_{A}^{l}\left(\mathrm{mJm}^{-2}\right)$ & $W_{A}\left(\mathrm{mJm}^{-2}\right)$ & $W_{A}^{l}\left(\mathrm{mJm}^{-2}\right)$ \\
\hline PP & 30.2 & 30.2 & 0.0 & 67.3 & -7.8 & 63.1 & -1.1 \\
\hline PA12 & 41.0 & 24.0 & 17.0 & 98.7 & -29.2 & 93.2 & -22.6 \\
\hline Vectra & 39.3 & 36.3 & 2.9 & 89.9 & -14.4 & 84.6 & -7.8 \\
\hline PPS & 40.6 & 33.7 & 6.9 & 95.7 & -19.4 & 90.1 & -12.8 \\
\hline Water & 72.2 & 22.0 & 50.2 & & & & \\
\hline Glass & 59.5 & 37.5 & 22.0 & & & & \\
\hline Silicon & 53.0 & 33.0 & 20.0 & & & & \\
\hline
\end{tabular}

occur in the PPS disks. However, residual stress may still play a part in determining adhesion, by causing any joint formed at high temperature to delaminate on cooling. The degree of residual stress at the interface developed in the PA12 joints may be lower than in the PPS joints, because of the much lower glass transition temperature of PA12 of $40{ }^{\circ} \mathrm{C}$, compared to that of PPS of $90{ }^{\circ} \mathrm{C}$. The use of atomic force microscopy as a direct measurement of adhesion force (for a review, see Schaefer and Gomez [14]) is currently under investigation and may help to separate out the work of adhesion and thermomechanical effects.

The values of the work of adhesion to glass and silicon for the various polymers in the presence of water are also given in Table V, calculated using (6). The negative values indicate that adhesion is thermodynamically unstable in the presence of water for all the polymer/glass or silicon combinations. An adhesion promoter would therefore be required in all cases to achieve moisture durable bonding.

\section{CONCLUSION}

The feasibility of a novel packaging method for microfluidic devices supporting robust fluidic interconnections by overmolding in an injection mold has been investigated. It has been demonstrated that brittle borosilicate glass and silicon inserts representing microfluidic devices, 20 by $25 \mathrm{~mm}$ in area, can be successfully overmolded with a variety of thermoplastic molding materials without breaking. The quality and reliability of the seal between overmold and inserts were tested by pressurization of an interconnection channel, with water at 1.4 bar for up to $24 \mathrm{~h}$, and by overpressurization at 6.9 bar for $60 \mathrm{~s}$. The best results for both silicon and glass were obtained with PA12, which is a low hygroscopicity PA. Good results were also obtained with an LCP, with glass but not silicon. The coating of glass inserts with a silane adhesion promoter improved the resistance of LCP overmolded samples to humidity conditioning but degraded the performance of PA12 samples. The ranking of polymers by their performance in the pressurization tests was consistent with the ranking by the calculated work-of-adhesion values for polymer/glass and polymer/silicon joints.

An attempt was made to use tensile tests with lap-jointed samples to compare more directly the adhesion strengths between the different polymers and glass. The only durable samples were obtained with PA12, with an average shear strength of $16.7 \mathrm{MPa}$. The production method for the lap joints may not be suitable for all polymers, particularly the LCP. The results obtained suggest that a reliable moisture-resistant seal between an overmold and an insert can be obtained for the right combination of processing conditions, adhesion promoter, and choice of molding material.

\section{ACKNOWLEDGMENT}

The authors would like to thank C. C. Hsu for the lap-jointed tensile testing.

\section{REFERENCES}

[1] E. Verpoorte and N. F. De Rooij, "Microfluidics meets MEMS," Proc. IEEE, vol. 91, no. 6, pp. 930-953, Jun. 2003.

[2] J. S. Custer, A. D. Oliver, and M. V. Collins, "Packaging of microsystems," in MEMS Packaging, T. R. Hsu, Ed. London, U.K.: INSPEC, 2004, pp. 85-178.

[3] MicroBUILDER Programme, Silicon/Polymer Integration. (accessed 20/05/2008). [Online]. Available: http://www.sintef.no/content/ page 1 14401.aspx2008

[4] A. J. Kinloch, Adhesion and Adhesives: Science and Technology. New York: Chapman \& Hall, 1987.

[5] K. Ma, T.-S. Chung, and R. J. Good, "Surface energy of thermotropic liquid crystalline polyesters and polyesteramide," J. Polym. Sci. B, Polym. Phys., vol. 36, no. 13, pp. 2327-2337, 1998.

[6] A. V. Pocius, Adhesion and Adhesives Technology: An Introduction. Cincinnati, OH: Hanser/Gardner, 2002.

[7] E. Pisanova and E. Maeder, "Acid-base interactions and covalent bonding at a fiber-matrix interface: Contribution to the work of adhesion and measured adhesion strength," J. Adhesion Sci. Technol., vol. 14, no. 3, pp. 415-436, 2000.

[8] C. P. Wong and T. Fang, "Fundamentals of sealing and encapsulation," in Fundamentals of Microsystems Packaging, R. R. Tummala, Ed. New York: McGraw-Hill, 2001, pp. 580-610.

[9] N. J. Teh, P. P. Conway, P. J. Palmer, S. Prosser, and A. Kioul, "Statistical optimisation of thermoplastic injection moulding process for the encapsulation of electronic subassembly," J. Electron. Manuf., vol. 10, pp. 171-179, 2000.

[10] D. M. Brewis and D. Briggs, Industrial Adhesion Problems. Oxford, U.K.: Orbital Press, 1985.

[11] F. Dreux, S. Marais, F. Poncin-Epaillard, M. Metayer, M. Labbe, and J.-M. Saiter, "Water and toluene barrier properties of a polyamide 12 modified by a surface treatment using cold plasma," Mater. Res. Innov., vol. 7, no. 3, pp. 183-190, Jun. 2003.

[12] W. Leahy, V. Barron, M. Buggy, T. Young, A. Mas, F. Schue, T. McCabe, and M. Bridge, "Plasma surface treatment of aerospace materials for enhanced adhesive bonding," J. Adhesion, vol. 77, no. 3, pp. 215-249, 2001.

[13] S.-W. Choi, W.-B. Choi, Y.-H. Lee, B.-K. Ju, M.-Y. Sung, and B.-H. Kim, "The analysis of oxygen plasma pretreatment for improving anodic bonding," J. Electrochem. Soc., vol. 149, no. 1, pp. G8-G11, Jan. 2002.

[14] D. M. Schaefer and J. Gomez, "Atomic force microscope techniques for adhesion measurements," J. Adhesion, vol. 74, pp. 341-359, 2000. 
D. Patrick Webb (M'06) received the degree in mathematical physics from the University of Manchester Institute of Science and Technology, Manchester, U.K., in 1988, and the Ph.D. degree in amorphous semiconductors from the University of Abertay Dundee, Dundee, U.K., in 1994.

He has been a Research Fellow with the Interconnection Group, Wolfson School of Mechanical and Manufacturing Engineering, Loughborough University, Loughborough, U.K., since 2000. His research interests include innovative packaging and integration solutions for electronics and microsystems. He is currently running projects in fluidic interconnection of microsystems and packaging of sensors and electronics for harsh environments.

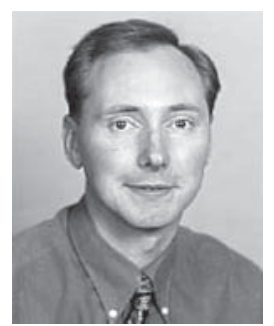

David A. Hutt (M'06-SM'06) received the B.Sc. degree in chemistry and the Ph.D. degree in surface science from Imperial College, London, U.K.

He studied fundamental surface chemistry/physics as a Research Associate at a number of U.K. universities. In 1997, he joined the Interconnection Group, Wolfson School of Mechanical and Manufacturing Engineering, Loughborough University, Loughborough, U.K., applying his background to the field of electronics manufacture. He was appointed to a lectureship in 1999 and is currently a Senior Lecturer. His research interests include high-density interconnect, fluxless soldering, and novel substrate manufacture.

Neil Hopkinson received the B.Eng. (Hons.) degree in manufacturing engineering and operations management from the University of Nottingham, Nottingham, U.K., and the Ph.D. degree in injection moulding using stereolithography tooling from De Montfort University, Leicester, U.K., under a sponsorship from 3D Systems.

He entered the "rapid" industry in 1996. He has secured more than \$5 million in research funding, with emphasis on rapid manufacturing. He is currently with the Wolfson School of Mechanical and Manufacturing Engineering, Loughborough University, Loughborough, U.K.

Dr. Hopkinson is the Lead Editor of the world's first book on rapid manufacturing and has been an Invited/Keynote Speaker and a Member of Scientific Panel for numerous conferences worldwide. He is also the lead inventor of highspeed sintering. He was voted by the readership of The TCT Magazine (Europe) as one of the top 25 most influential people in the industry over the last 15 years.
Paul P. Conway (SM'90) received the B.S. degree (with first class honors) from the University of Ulster, Belfast, U.K., in 1988, and the M.Sc. degree from Loughborough University, Loughborough, U.K., in 1989.

$\mathrm{He}$ is currently a Professor of manufacturing processes with the Wolfson School of Mechanical and Manufacturing Engineering, Loughborough University, and the Director of the Research Council's U.K. Innovative Electronics Manufacturing Research Center. He previously worked as a Research Assistant on a project addressing process modeling of reflow soldering and, prior to that, as an Industrial Engineer with Fisher Body Overseas Corporation, General Motors Corporation. He has held a number of substantial Research Council, European Framework Programme, and industrially funded research projects and has published widely in the field of electronics manufacturing technology.

$\mathrm{Mr}$. Conway was the recipient of the Institution of Production Engineers-Shorts Brothers PLC Prize.

Paul J. Palmer (M'99-SM'05) received the first degree in physics and the M.S. degree in manufacturing systems engineering.

In 1998, he joined Loughborough University, Loughborough, U.K., splitting his time primarily between research and technology transfer activities. He is currently a Senior Research Fellow with Loughborough University and the Director of the Integrated Products Manufacturing Knowledge Transfer Network (KTN). He has been involved in a number of "firsts"-including helping to commission the U.K.'s first microprocessor-controlled nuclear reactor test and monitoring system, and working on the manufacture of the U.K.'s first driverless trains for the London Docklands Light Railway. He ran his own technical consultancy for several years, providing manufacturing advice and writing specialist software. He has interests in electronic design, manufacturing processes, cost modeling, technology roadmapping, and associated tools and methodologies and has extensively worked with industry and academia. 